\title{
Aging in America and Meals on Wheels: Exploring Impacts on Food Insecurity, Health Outcomes, and Hospitalizations
}

Visakha Som ${ }^{1 *}$, Darlene Yee-Melichar ${ }^{2}$ and Mary Louise Zernicke ${ }^{3}$

${ }^{1}$ Public Administration Program, San Francisco State University, USA

${ }^{2}$ Gerontology Program, San Francisco State University, USA

${ }^{3}$ Nutrition and Dietetics, Merritt College, USA

\begin{abstract}
In the U.S., the 65 and older demographic is expected to double in size by 2050 and with older adults accounting for more than a third of hospital stays, it can be expected that the portion of hospital stays by older adults will increase accordingly. One program that has been linked to reducing hospitalizations and improving health outcomes is Meals on Wheels (MOW). Secondary analysis of existing data from the Eighth National Survey of OAA Participants was conducted to explore the impact of MOW service on health outcomes, hospitalizations, and food insecurity while focusing on the following research question: does MOW service reduce the number of hospitalizations and improve health outcomes, and if so, how does the length of service influence these relationships? This research showed that respondents to the survey have high levels of selfreported health improvement ( 76.1 to $91.5 \%$ ) and low levels of food insecurity (9.4 to $29.7 \%$ ) after MOW participation. Thirty-seven percent report being hospitalized in the last 12 months. Overall, the findings suggest that as the length of MOW service increases, improved health outcomes increase while hospitalizations decrease. The findings indicate that the length of service has no significant correlation to food insecurity, likely because the typical number of meals per week is relatively low (five to seven per week) and does not vary. Policy makers at the federal, state and local levels will need to plan for future MOW needs by increasing funding and recognizing MOW as a medically necessary intervention in preventing or reducing hospitalizations and improving the lives of its participants. Future research should study whether additional meals beyond the typical five to seven meals per week would significantly change how MOW service influences the levels of health outcomes, hospitalizations, and food insecurity.
\end{abstract}

Keywords

Senior nutrition, Meals on wheels, Older adults, Hospitalization, Readmissions, Health outcomes, Food insecurity

Abbreviations

AAA: Area Agency on Aging; ACA: Affordable Care Act; AOA: Administration on Aging; HCBS: Home and communitybased services; LTSS: Long term services and supports; MOW: Meals on Wheels; OAA: Older Americans Act

\section{Introduction}

Over the next few decades, the U.S. will undergo a major shift in demographics. The Baby Boomers have begun approaching the 65 and older demographic and are expected to double to 88.5 million people by 2050 [1]. The 2014 U.S. Census Bureau reports that the average life expectancy will increase from 79.4 years in 2015 to 84.4 years in 2050 [1]. In addition, the lifetime probability of becoming disabled or of being cognitively impaired is $68 \%$ for people aged 65 and older [2]. The healthcare implications of this shift are tremendous. A study by Wier, Pfunter, and Steiner [3] indicated that in 2008, adults 65 and older accounted for $13 \%$ of the U.S. population and
$35 \%$ of hospital stays with an associated cost of $\$ 157.7$ billion dollars. With the dramatic increase of the older adult population, it can be expected that the number of older adult hospitalizations will increase accordingly.

*Corresponding author: Visakha Som, MPA, Research Associate, Public Administration Program, San Francisco State University, USA, E-mail: vsom@mail.sfsu.edu

Received: February 17, 2016; Accepted: May 15, 2017; Published online: May 17, 2017

Citation: Som V, Yee-Melichar D, Zernicke ML (2017) Aging in America and Meals on Wheels: Exploring Impacts on Food Insecurity, Health Outcomes, and Hospitalizations. Trends Geriatr Healthc 1(1):23-30.

Copyright: (c) 2017 Som V, et al. This is an open-access article distributed under the terms of the Creative Commons Attribution License, which permits unrestricted use, distribution, and reproduction in any medium, provided the original author and source are credited. 
Citation: Som V, Yee-Melichar D, Zernicke ML (2017) Aging in America and Meals on Wheels: Exploring Impacts on Food Insecurity, Health Outcomes, and Hospitalizations. Trends Geriatr Healthc 1(1):23-30.

Food insecurity and the impact of malnutrition on health becomes a critical concern for aging Baby Boomers. The U.S. Government Accountability Office [4] reports an increase in food insecurity amongst low-income older adults ${ }^{\mathrm{a}}$ to about 24 percent in 2013 from 19 percent in 2008. Malnutrition, primarily as under nutrition, is common amongst hospitalized older adults at both the time of admission and upon discharge [5]. Soenen and Chapman [6] report 62 percent of older hospitalized patients experience under nutrition.

Meals on Wheels (MOW) is a home- and community-based program that has been linked to reduction of hospitalizations. MOW delivers nutritious meals to the residences of homebound seniors who are unable to obtain or/and prepare meals. Most MOW programs receive a bulk of the funding through the Older Americans Act (OAA) Nutrition Program, a federal program whose program goals include improving health, reducing malnutrition, decreasing social isolation, and delaying adverse health conditions among older adults [7]. Various studies [8-10] indicate that hospitalizations are reduced when paired with MOW. Another study found that older adults who received home-delivered meals have greater improvements in self-rated health and lower rates of hospitalizations when compared to the control group that did not receive meals [11].

To build on this emerging body of research, we conducted secondary analysis of existing data from the Eighth National Survey of OAA Participants to explore the impact of MOW service on health outcomes, hospitalizations, and food insecurity while focusing on the following research question: does MOW service reduce the number of hospitalizations and improve health outcomes, and if so, how does the length of service influence these relationships?

For this research, we considered these program goals: 1) MOW promotes health and delays adverse health conditions, and 2) MOW reduces food insecurity while reducing malnutrition. We generated a set of hypotheses based on the findings of prior research. The research article continues with an overview of the dataset and variables being discussed and is followed by a presentation of findings. The article concludes with policy implications and considerations for further research.

\section{The links between MOW, food insecurity, health outcomes and hospitalizations}

In 2008, there were more than 14 million hospital

aLow-income is defined by GAO as households with incomes below 185 percent of the poverty threshold (U.S. Government Accountability Office, 2015), which in 2013 was $\$ 21,265$ annually for a single person household (Centers for Medicare and Medicaid Services). stays among adults aged 65 years and older. These hospitalizations accounted for $35 \%$ of U.S. community hospital stays and about 14 percent ( $\$ 157.7$ billion) of total hospital costs [3]. One study revealed that $19 \%$ of Medicare patients (ages 65 and up) were re-admitted to hospitals within 30 days of initial discharge [12].

A 15-week pilot study called More Than a Meal found that older adults who received home-delivered meals have greater improvements in self-rated health and reduced rates of hospitalizations when compared to the control group that did not receive meals. In the category of self-reported health, $29 \%$ of the sample group reported improvements, a $6 \%$ increase from the control group. The study also found that " $14 \%$ of individuals who received meals were hospitalized during the study period compared to $20 \%$ of individuals in the control group" [11].

Home delivery of meals to recently discharged older adults reduces hospital readmissions. One study observed a $61 \%$ decrease in readmissions when home-based services like MOW were offered; $30 \%$ of the participants received MOW [8]. In a study by McKay [9], 25 geriatric patients were recruited to participate in a nutrition intervention program that included home-delivered meals. Of the 13 participants who completed the entire 60-day program, only one patient was readmitted within 30 days of discharge [9]. In another study, home-delivered meals were provided to 121 participants who were defined as high-risk for emergent care and $24.7 \%$ were hospitalized within 90 days of discharge [10].

Since one of the program goals of MOW is to promote health and delay adverse conditions and previous studies suggest that home-delivered meals reduce hospitalizations and improve health outcomes, we can expect that MOW service has an impact on hospital stays and self-reported health outcomes with two specific hypotheses:

Hypothesis 1: Length of MOW service is positively correlated with self-reported health outcomes.

Hypothesis 2: Length of MOW service is negatively correlated with hospitalizations in the last 12 months.

Food insecurity amongst older adults in the U.S. has grown, from $5.5 \%$ in 2001 to $8.3 \%$ in 2015 [13]. With the number of Baby Boomers aging, food insecurity and the impact of malnutrition on health becomes an increasingly critical concern. The U.S. Government Accountability Office reports an increase in food insecurity amongst low-income older adults, from 19 percent in 2008 to 24 percent in 2013 [4]. Malnutrition is common amongst hospitalized older adults at both the time of admission and upon discharge [5]. Malnourished older adults have increased length of stay in hospitals, increased readmis- 
Citation: Som V, Yee-Melichar D, Zernicke ML (2017) Aging in America and Meals on Wheels: Exploring Impacts on Food Insecurity, Health Outcomes, and Hospitalizations. Trends Geriatr Healthc 1(1):23-30.

Table 1: Summary of variables and statistics.

\begin{tabular}{|c|c|c|c|c|c|c|c|c|}
\hline \multirow{2}{*}{\multicolumn{2}{|c|}{ Statistics }} & \multicolumn{2}{|l|}{$\mathbf{N}$} & \multirow{3}{*}{$\begin{array}{l}\text { Mean } \\
2.76\end{array}$} & \multirow{3}{*}{$\begin{array}{l}\text { Median } \\
3.00\end{array}$} & \multirow{3}{*}{$\begin{array}{l}\text { Mode } \\
4.00\end{array}$} & \multirow{3}{*}{$\begin{array}{l}\text { SD } \\
1.24\end{array}$} & \multirow{3}{*}{$\begin{array}{l}\text { Var } \\
1.53\end{array}$} \\
\hline & & \multirow[b]{2}{*}{\begin{tabular}{|l} 
Valid \\
1043
\end{tabular}} & \multirow{2}{*}{$\begin{array}{l}\text { Missing } \\
35\end{array}$} & & & & & \\
\hline $\begin{array}{l}\stackrel{ }{\frac{c}{o}} \\
\frac{0}{0} \\
\frac{0}{0} \\
\frac{0}{0}\end{array}$ & $\begin{array}{l}\text { Length of Service } \\
(1=6 \text { months or less, } 2=\text { More than } 6 \\
\text { months but less than } 1 \text { year, } 3=\text { At least } 1 \\
\text { year but less than } 2 \text { years, } 4=2 \text { to } 5 \text { years, } 5 \\
=\text { more than } 5 \text { years) }\end{array}$ & & & & & & & \\
\hline \multirow{8}{*}{ 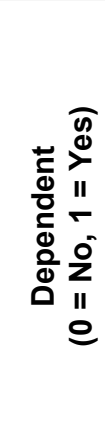 } & Meals improve my health & 969 & 109 & 0.85 & 1.00 & 1.00 & 0.36 & 0.13 \\
\hline & Meals help me stay in home & 1061 & 17 & 0.93 & 1.00 & 1.00 & 0.26 & 0.07 \\
\hline & Meals helps me feel better & 1022 & 56 & 0.91 & 1.00 & 1.00 & 0.29 & 0.08 \\
\hline & $\begin{array}{l}\text { Choose between buying food and buying } \\
\text { medication in the past month }\end{array}$ & 1062 & 16 & 0.18 & 0.00 & 0.00 & 0.38 & 0.15 \\
\hline & $\begin{array}{l}\text { Choose between buying food and paying rent } \\
\text { or utility bills in the past month }\end{array}$ & 1067 & 11 & 0.14 & 0.00 & 0.00 & 0.35 & 0.12 \\
\hline & $\begin{array}{l}\text { Skipped meals because no money or food } \\
\text { stamps to buy food in the past month }\end{array}$ & 1071 & 7 & 0.09 & 0.00 & 0.00 & 0.29 & 0.09 \\
\hline & Not enough money or food stamps & 1061 & 17 & 0.29 & 0.00 & 0.00 & 0.45 & 0.21 \\
\hline & Hospitalized in the last 12 months & 1072 & 6 & 0.37 & 0.00 & 0.00 & 0.48 & 0.23 \\
\hline
\end{tabular}

\section{Percentage of Respondents with "Yes" Responses (N=1078)}

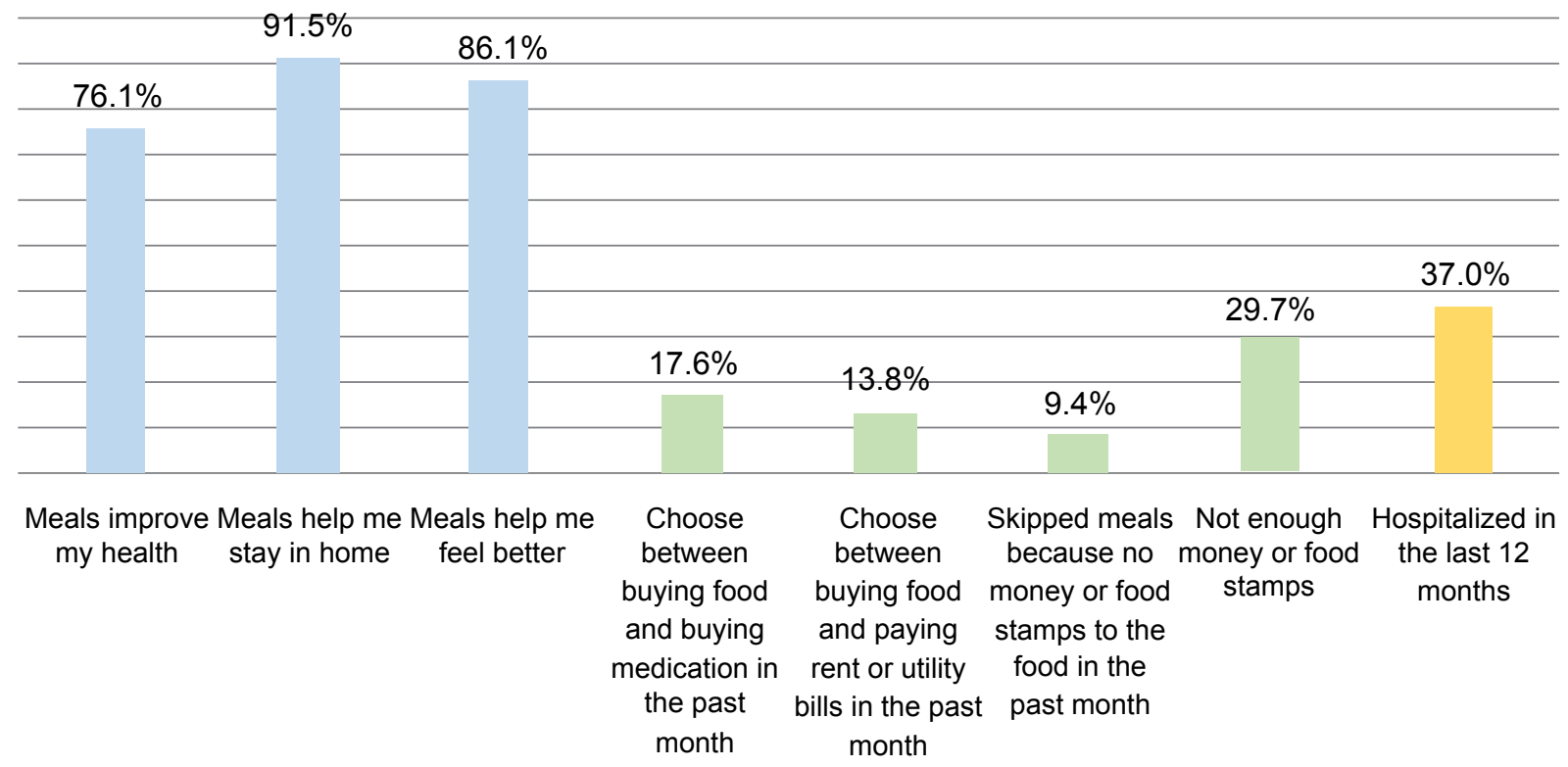

Figure 1: Percentage of respondents with "yes" responses chart.

sions, and greater mortality rates when compared to older adults who were not malnourished [14]. Another study found that there is a $60 \%$ increased risk in hospital readmissions within 15 days for malnourished patients when compared to well-nourished patients [15].

With 63 percent of MOW participants reporting an annual income less than $\$ 20,000$ [7], it is not surprising that MOW participants have trouble meeting their nutritional needs. While there are a variety of factors that lead to malnutrition among older adults, food insecurity is considered the most significant factor ${ }^{\mathrm{b}}$.

Given the finding of the studies discussed above and that one of MOW's program goals is to reduce food insecurity for participants, we can expect that MOW participants are more food secure with a third specific hypothesis:

Hypothesis 3: Length of MOW services is negatively correlated with food insecurity levels.

\section{Materials and Methods}

To test the hypotheses indicated above, we conducted secondary analysis of existing data from the Eighth

${ }^{\mathrm{b}}$ The validated DETERMINE Checklist, a measure of nutrition risk administered to all MOW clients at intake and annually, assigns the greatest risk for malnutrition to a lack of funds to purchase needed food (National Resource Center on Nutrition \& Aging, 2016). 
Citation: Som V, Yee-Melichar D, Zernicke ML (2017) Aging in America and Meals on Wheels: Exploring Impacts on Food Insecurity, Health Outcomes, and Hospitalizations. Trends Geriatr Healthc 1(1):23-30.

National Survey of OAA Participants completed in 2013. The survey employed a two-phase sample design that first selected a sample of Area Agencies on Aging (AAA). The second phase randomly selected participants from each selected AAA by service type, including MOW. The total number of older adults in the sampling frame for the Meals on Wheels service type was 1,078 participants. The survey contains 292 variables; the variables included questions about health, diet, access and utilization of benefits, and service satisfaction.

Several variables were extracted that are related to health outcomes and food insecurity. Variables in their original form were analyzed in SPSS and the resulting descriptive data were used to determine baseline characteristics; Table 1 provides a summary of the variables and the statistics.

Figure 1 is a visual representation of the percentage of respondents who replied "yes" to the survey questions. When compared to the studies discussed above, the data suggests that the survey respondents have high levels of improved health outcomes $(79.1 \%$ to $86.1 \%) ; 29.7 \%$ of respondents report not having enough money or food stamps to buy needed food; $9.4 \%$ report having to skip meals in the past month due to not having enough money or food stamps; $17.6 \%$ report having to choose between buying food and medication in the past month. These numbers are higher than the national older adult average of $8.3 \%$ [13] and appear to reflect the fact that MOW serves proportionately more low income seniors, since $63 \%$ of respondents report an annual income of less than $\$ 20,000$ [7]. Since these income levels fall within the definition of low-income for a single adult household, we can make comparisons to the 2013 figure that states that $24 \%$ of low-income older adults are food insecure (Older Americans Act: Updated Information on Unmet Needs for Services, 2015) [4]. Thirty-seven percent of respondents report being hospitalized in the last 12 months.

These comparisons prompt us to further examine the role of MOW and whether there is a direct correlation of MOW service to dependent variables. Bivariate analyses were conducted in SPSS to measure the strength of associations between the independent and dependent variables and the direction of the relationship. The independent variable (length of service) was transformed into dichotomous variables.

\section{Limitations}

There are several factors that cannot be controlled for in this research. The 2013 survey did not ask questions regarding other factors that can have effect on the research including how many meals are delivered each week (rarely do local MOW programs provide more than one meal a day), if and how long they waited for the initiation of service, and other barriers to receiving adequate nutrition such as tooth and mouth problems, and an ability to get food from the grocery store to provide additional meals/nutrition. In addition, there are no questions that asked participants why they started MOW and how many times they had been hospitalized within the last year. These two missing aspects play crucial roles in testing the hypotheses. The survey asks several specific questions about medical conditions such as "has a doctor ever told you that you have heart disease?" however; there is no question that asks "has a doctor ever told you that you are malnourished?".

\section{Results}

Descriptive statistics in Table 1 suggest that MOW service greatly improves self-reported outcomes, whereas in the More Than a Meal pilot study, only $27 \%$ of par-

Table 2: Correlation matrix: Length of service variables*Self-reported improvement variables.

\begin{tabular}{|c|c|c|c|c|}
\hline & & $\begin{array}{l}\text { Meals improve my } \\
\text { health }\end{array}$ & $\begin{array}{l}\text { Meals help me stay in } \\
\text { home }\end{array}$ & $\begin{array}{l}\text { Meals help me feel } \\
\text { better }\end{array}$ \\
\hline \multirow{3}{*}{$\begin{array}{l}\text { Less than } 6 \\
\text { months }\end{array}$} & Pearson Correlation & -0.140 & -0.053 & -0.121 \\
\hline & Sig. (2-tailed) & 0.000 & 0.086 & 0.000 \\
\hline & $N$ & 969 & 1061 & 1022 \\
\hline \multirow{3}{*}{$\begin{array}{l}\text { Between } 6 \text { months } \\
\text { and } 1 \text { year }\end{array}$} & Pearson Correlation & 0.015 & -0.005 & 0.029 \\
\hline & Sig. (2-tailed) & 0.641 & 0.859 & 0.349 \\
\hline & $N$ & 969 & 1061 & 1022.0 \\
\hline \multirow{3}{*}{$\begin{array}{l}\text { Between } 1 \text { year } \\
\text { and } 2 \text { years }\end{array}$} & Pearson Correlation & 0.052 & 0.006 & 0.013 \\
\hline & Sig. (2-tailed) & 0.103 & 0.855 & 0.667 \\
\hline & $N$ & 969 & 1061 & 1022 \\
\hline \multirow{3}{*}{$\begin{array}{l}\text { Between } 2 \text { years } \\
\text { and } 5 \text { years }\end{array}$} & Pearson Correlation & $0.077^{*}$ & $0.060^{*}$ & 0.057 \\
\hline & Sig. (2-tailed) & 0.016 & 0.049 & 0.069 \\
\hline & $N$ & 969 & 1061 & 1022 \\
\hline \multirow[t]{3}{*}{ Five years or more } & Pearson Correlation & 0.000 & -0.032 & 0.002 \\
\hline & Sig. (2-tailed) & 0.999 & 0.296 & 0.943 \\
\hline & $N$ & 969 & 1061 & 1022 \\
\hline
\end{tabular}


Citation: Som V, Yee-Melichar D, Zernicke ML (2017) Aging in America and Meals on Wheels: Exploring Impacts on Food Insecurity, Health Outcomes, and Hospitalizations. Trends Geriatr Healthc 1(1):23-30.

ticipants reported an improvement in health outcomes. The difference in these findings may be explained by the length of service (varying lengths of service compared to the 15-week pilot study). Correlation tests were conducted to determine if the length of MOW service is positively correlated with improved self-reported health outcomes (H1). Results in Table 2 indicate several statistically significant correlations. When examining the "Less than 6 months" of MOW service, we can see that there are significant correlations $(p<0.05)$ with "meals improve my health" and "meals helps me feel better"; however, the Pearson coefficients are negative, indicating an inverse relationship. If the alpha is at $10 \%$, then we can accept there is a small negative correlation between "less than 6 months" of MOW service and all three outcome variables. If the alpha is set at $10 \%$, another set of significant correlations exist when outcome variables are compared to "between 2 years and 5 years" of MOW service, indicating a small positive correlation. All three indicators suggest that having MOW for two to five years is associated with improved self-reported health outcomes. The relationship is modest (small coefficients), but statistically fairly strong. There are no significant correlations when the length of MOW service is between 6 months and 1 year, 1 year and 2 years, and more than five years. Given the inconsistency, $\mathrm{H} 1$ is not supported.
Thirty-seven percent of survey respondents indicated being hospitalized in the last 12 months. Descriptive statistics in Figure 2 suggests that as the length of MOW service increases, the percentage of respondents who have been hospitalized while receiving home delivered meals decreases.

We hypothesize that as the length of meal service increases, the rate of hospitalization decreases (H2). Correlation tests Table 3 indicate that, as the length of service increases, the rate of hospitalizations decreases. Four of the five lengths of service variables are statistically significant (p-values ranging from 0.000 to 0.032 ). However, to determine the direction of the relationship between these variables, further research is needed.

As indicated in Figure 1, survey respondents report "yes" to several indicators of food insecurity. The results of the correlation results Table 4 suggest that length of service has no significant correlation to food insecurity indicators.

\section{Discussion and Policy Implications}

This research shows that respondents to the survey have high levels of self-reported health improvement (76.1 to $91.5 \%$ ) and low levels of food insecurity (9.4 to 29.7\%) given MOW participation. Over a third of re-

Percentage of Hospitalization by Length of Service

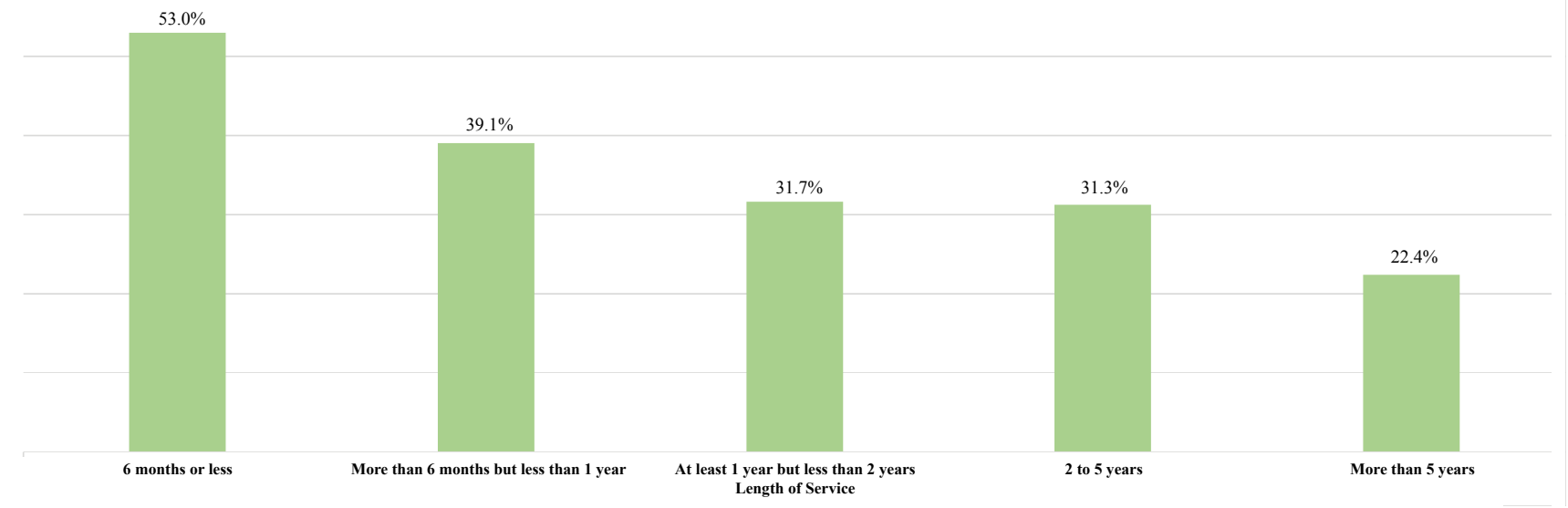

Figure 2: Chart: length of service variables*Hospitalizations variable.

Table 3: Correlation matrix: Length of service variable*Hospitalizations variable.

\begin{tabular}{|c|c|c|c|c|c|c|c|}
\hline & & $\begin{array}{l}\text { Less than } \\
6 \text { months }\end{array}$ & $\begin{array}{l}\text { Between } 6 \\
\text { months and } \\
1 \text { year }\end{array}$ & $\begin{array}{l}\text { Between } 1 \\
\text { year and } 2 \\
\text { years }\end{array}$ & $\begin{array}{l}\text { Between } 2 \\
\text { years and } 5 \\
\text { years }\end{array}$ & $\begin{array}{l}\text { Five years } \\
\text { or more }\end{array}$ & $\begin{array}{l}\text { Hospitalized } \\
\text { in the last } 12 \\
\text { months }\end{array}$ \\
\hline \multirow{3}{*}{$\begin{array}{l}\text { Hospitalized } \\
\text { in the last } 12 \\
\text { months }\end{array}$} & Pearson Correlation & $.172^{* *}$ & 0.018 & $-.065^{*}$ & $-.075^{*}$ & $-.073^{*}$ & 1 \\
\hline & Sig. (2-tailed) & 0.000 & 0.560 & 0.032 & 0.014 & 0.016 & \\
\hline & $N$ & 1072 & 1072 & 1072 & 1072 & 1072 & 1072 \\
\hline
\end{tabular}


Citation: Som V, Yee-Melichar D, Zernicke ML (2017) Aging in America and Meals on Wheels: Exploring Impacts on Food Insecurity, Health Outcomes, and Hospitalizations. Trends Geriatr Healthc 1(1):23-30.

Table 4: Correlation matrix: Length of service variable*Food insecurity variables.

\begin{tabular}{|c|c|c|c|c|c|c|}
\hline & & $\begin{array}{l}\text { Less than } \\
6 \text { months }\end{array}$ & $\begin{array}{l}\text { Between } \\
6 \text { months } \\
\text { and } 1 \text { year }\end{array}$ & $\begin{array}{l}\text { Between } 1 \\
\text { year and } 2 \\
\text { years }\end{array}$ & $\begin{array}{l}\text { Between } 2 \\
\text { years and } \\
5 \text { years }\end{array}$ & $\begin{array}{l}\text { Five } \\
\text { years or } \\
\text { more }\end{array}$ \\
\hline \multirow{3}{*}{$\begin{array}{l}\text { Choose between buying food and } \\
\text { buying medication in the past month }\end{array}$} & Pearson Correlation & -0.008 & 0.019 & 0.003 & -0.002 & -0.007 \\
\hline & Sig. (2-tailed) & 0.797 & 0.530 & 0.913 & 0.950 & 0.810 \\
\hline & $N$ & 1062 & 1062 & 1062 & 1062 & 1062 \\
\hline \multirow{3}{*}{$\begin{array}{l}\text { Choose between buying food and } \\
\text { paying rent or utility bills in the past } \\
\text { month }\end{array}$} & Pearson Correlation & -0.036 & -0.011 & 0.012 & 0.059 & -0.036 \\
\hline & Sig. (2-tailed) & 0.237 & 0.724 & 0.705 & 0.055 & 0.245 \\
\hline & $N$ & 1067 & 1067 & 1067 & 1067 & 1067 \\
\hline \multirow{3}{*}{$\begin{array}{l}\text { Skipped meals because no money or } \\
\text { food stamps to buy food in the past } \\
\text { month }\end{array}$} & Pearson Correlation & -0.008 & 0.017 & -0.009 & 0.027 & -0.034 \\
\hline & Sig. (2-tailed) & 0.805 & 0.588 & 0.776 & 0.378 & 0.269 \\
\hline & $N$ & 1071 & 1071 & 1071 & 1071 & 1071 \\
\hline \multirow[t]{3}{*}{ Not enough money or food stamps } & Pearson Correlation & -0.027 & 0.049 & 0.033 & -0.023 & -0.040 \\
\hline & Sig. (2-tailed) & 0.388 & 0.114 & 0.287 & 0.459 & 0.193 \\
\hline & $N$ & 1061 & 1061 & 1061 & 1061 & 1061 \\
\hline
\end{tabular}

spondents (37\%) report being hospitalized in the last 12 months. Though not conclusive, our study reveals some interesting trends that are worth noting.

First, the data suggest that in the first six months of MOW service, respondents cannot attribute improved health outcomes to MOW service; in fact, the data suggests that meals are negatively correlated with outcome variables However, as the length of service increases to 2 years to 5 years, more respondents attribute MOW to improving their health and the correlations become statistically significant ( $p$ values range from 0.016 to 0.069 ); the correlation is not statistically significant for respondents who have participated in MOW for more than 5 years.

The study also indicates that the lengths of service variables are correlated with hospitalizations. The direction of the correlation changes from positive to negative as the length of service time increases. The initial positive correlation during the twelve months of MOW service can be explained by two possible factors: 1) Respondents are asked if they are hospitalized in the last year, regardless if they had been on MOW service for 1 week or 10 years, and 2) A recent hospitalization is one way to enter the program. Without data indicating why an older adult entered the MOW program or additional data on hospitalizations (how many in a year and when), these factors can potentially change the relationships between variables from dependent to independent and vice versa. Based on this analysis, it can be said that respondents in their first twelve months of service experience more hospitalizations than respondents who have been on MOW service for longer lengths of time.

This study reveals that length of service variables have no significant correlation to food insecurity variables. This may be in part because: 1) The typical number of meals served is five to seven per week, and 2) The num- ber of meals does not change. To determine if MOW service has an impact on food insecurity, further research is needed that looks at food insecurity indicators before entry into the MOW program and periodically afterc .

A key finding in this research is that $29.7 \%$ of respondents report not having enough money or food stamps to buy needed food, indicating some level of food insecurity and unmet nutritional needs. Furthermore, the U.S. Government Accountability Office (2015) reported that an estimated 90 percent of low-income older adults do not receive meals services like those funded by the OAA. Federal funding for MOW and other OAA programs have remained flat ( $\$ 1.80$ billion in FY 2004 to $\$ 1.88$ billion in FY 2014) despite the fact that the 60 and older demographic has grown by $30 \%$ during the same time frame. It is recommended that federal policy makers increase funding to meet this unmet need and to insulate MOW from future budget cuts.

As the rates of food insecurity increase with the increased number of seniors, policy makers at the federal, state and local levels will need to plan for future MOW needs, while simultaneously helping MOW reposition itself nationally as a medically necessary intervention in preventing or reducing hospitalizations and improving the lives of its participants. In addition, researchers should study whether additional food beyond the typical five to seven meals per week would significantly change influences levels of health outcomes, hospitalization and food insecurity. Future research is recommended that isolates cases in which respondents indicate having to choose to between buying food and buying medication and compares health outcomes and hospitalization variables to the larger MOW survey respondents group.

'The DETERMINE checklist, which is conducted at intake and annually thereafter, can determine if MOW has an impact of food insecurity. 
Citation: Som V, Yee-Melichar D, Zernicke ML (2017) Aging in America and Meals on Wheels: Exploring Impacts on Food Insecurity, Health Outcomes, and Hospitalizations. Trends Geriatr Healthc 1(1):23-30.

Since the later 1970s, policy makers have introduced a series of policy initiatives and demonstrations to encourage care coordination across a spectrum of care [16] and under the ACA, access to HCBS services is expected to increase through the care coordination between medical care and long-term services and supports (LTSS) systems (The SCAN Foundation, 2015). However, Browdie [16] asserts that care coordination is difficult to implement. One study focused on the challenges of delivering nutrition services like MOW to recently discharged older adults and found that referrals from hospitals came slower than anticipated. The study concluded that hospitals need incentives to refer to nutrition services and insurers need to be engaged to show the benefits of home delivered nutrition services [17]. Locher and Wellman [18] argue that these "two parallel but non-intersecting systems" exacerbate malnutrition in recently discharged older adults due to the lack of coordination and the limited availability of nutrition services.

ACA initiatives like the Hospital Readmission Reduction Program and Partnership for Patients initiatives have offered opportunities for programs like MOW to position themselves as affordable, effective, and accessible interventions to reduce hospital readmissions and bridge the coordination discussed above. However, to date, a repeal of ACA is being considered, resulting in uncertainty about the continuation of these initiatives.

Local governments as well as nonprofits will need to innovate their service delivery systems to appeal to hospitals and medical professionals as a medically necessary intervention. Insurers should consider MOW as a reimbursable and medically necessary service.

Finally, hunger and food insecurity reflect addition social service needs, including the need for case management, chore workers, home care, respite care, friendly visitors and information and assistance for frail and homebound seniors. MOW programs can support seniors to remain in their homes by having referral options to appropriate and affordable resources. Many frail and homebound older adults need assistance to access benefits and navigate the system of care, which can then decrease the reliance on MOW service. In some cases, MOW in partnership with other services may meet the needs of the older adult; in other cases, MOW is the triage or point of entry for further services. This case management approach is focused on independence, dignity, and sustainability and is customized to individual needs. Therefore, it is recommended that policy makers provide incentives for MOWs to provide case management services to MOW participants and customize meal plans for individualized needs.

\section{Acknowledgements}

The authors would like to thank the Meals on Wheels (MOW) recipients and their community program advocates for active participation in this research project. We would like to acknowledge Dr. Janey Wang and Dr. Jennifer Shea, SF State Public Administration faculty, for their helpful feedback on early drafts of this manuscript.

\section{References}

1. Ortman J, Velkoff V, Hogan H (2014) An Aging Nation: The Older Population in the United States. 25-1140.

2. Family Caregiver Alliance (2015) Selected Long-Term Care Statistics.

3. Wier L, Pfuntner A, Steiner C (2010) Hospital Utilization Among Oldest Adults, 2008: Healthcare Cost and Utilization Project (HCUP): Statistical Briefs. Agency for Healthcare Research and Quality.

4. Older Americans Act: Updated Information on Unmet Needs for Services. Briefing for Congressional Staff, Subcommitte on Primary Health and Retirement Security, U.S Government Accountability Office.

5. Heersink J, Brown C, Dimaria-Ghalili R, et al. (2010) Undernutrition in Hospitalized Older Adults: Patterns and Correlates, Outcomes, and Opportunities for Intervention with a Focus on Processes of Care. J Nutr Elderly 29: 4-41.

6. Soenen S, Chapman IM (2013) Body Weight, Anorexia, and Undernutrition in Older People. J Am Med Dir Assoc 14: 642-648.

7. Kowlessar N, Robinson K, Schur C, et al. (2015) Older Americans Benefit from Older Americans Act Nutrition Programs. Research Brief, U.S. Department of Human and Health Services, Administration on Aging.

8. Watkins L, Hall C, Krin D (2012) Hospital to Home: A Transition Program for Frail Older Adults. Professional Case Management 17: 117-123.

9. McKay D, Wilson J, Martin C, et al. (2000) The Impact of Home Delivered Meals on Elderly Patients. Care Management 6: 32 .

10. Cho J, Thorud JL, Marishak-Simon S, et al. (2015) A Model Home-Delivered Meals Program to Support Transitions from Hospital to Home. J Nutr Gerontol Geriatr 34: 201-217.

11. Thomas K, Dosa D (2015) More Than A Meal: Pilot Research Study.

12. Wier L, Barrett M, Steiner C, et al. (2011) All-Cause Readmission by Payer and Age, 2008. Agency for Healthcare Research and Quality, Rockville.

13. National Council on Aging (2016) Senior Hunger Fact Sheet.

14. Meals on Wheels America (2017) Hunger in Older Adults: Challenges and Opportunities for the Aging Services Network.

15. Lim SL, Ong KC, Chan YH, et al. (2012) Malnutrition and its impact on cost of hospitalization, length of stay, readmission and 3-year mortality. Clin Nutr 31: 345-350.

16. Browdie R (2013) Why is Care Coordination So Difficult to Implement? Generations 37: 62-67. 
Citation: Som V, Yee-Melichar D, Zernicke ML (2017) Aging in America and Meals on Wheels: Exploring Impacts on Food Insecurity, Health Outcomes, and Hospitalizations. Trends Geriatr Healthc 1(1):23-30.

17. Sahyoun NR, Akobundu U, Coray K, et al. (2009) Challenges in the Delivery of Nutrition Services to Hospital Discharged Older Adults. J Nutr Elderly 28: 127-142.
18. Locher J, Wellman N (2011) "Never the Twain Shall Meet:" Dual Systems Exacerbate Malnutrition in Older Adults Recently Discharged from Hospitals. J Nutr Gerontol Geriatr 30: 24-28. 